\title{
Sjögren's Syndrome Associated with Renal Tubular Acidosis, Medullary Sponge Kidney and Multiple Immunological Abnormalities
}

\author{
Norio Waseda, MD, Hiroyuki Ogawa, M D, Masaju Sano, M D, \\ Takashi Fujita, M D,Tokugoro Tsunematsu, M D \\ and Masaichi FuKaSE, M D
}

The Second Department of Internal Medicine, Faculty of Medicine, Kyoto University

Akira Shima, M D and Katsuro Miura, M D

Saiseikai Noe Hospital, Osaka

\begin{abstract}
A 20-year-old Japanese female was admitted to hospital with quadriplegia and arthralgia. Three years previous to admission proteinuria and polyarthralgia were evidenced and the following year erythematous eruptions on both cheeks and upper extremeties, quadriplegia, high fever and stomatitis developed. A hypopotassemia was also present. Since that time she had recurrent attacks of painful swelling of both parotid glands, myalgia, alopecia and nodular erythema. She had also passed urinary stones without concomitant pain or fever. A metabolic acidosis with hypopotassemia was demonstrated in the arterial blood. The urine was alkaline and urine concentrating ability was impaired. Inadequate urinary acidification was evident after administration of ammonium chloride. Such findings supported the diagnosis of renal tubular acidosis (RTA) of the distal type. An intravenous pyelogram (IVP) suggested medullary sponge kidney (MSK). Hypergammaglobulinemia was accompanied by multiple immunological abnormalities such as positive anti-thyroid antibodies and the evidence for anti-nuclear and anti-DNA antibodies. Biopsy specimens of the kidney, salivary and thyroid glands showed small, round cell infiltration in the interstitial tissues. Although sicca syndrome was not prominent, salivary secretion was decreased and a sialectasis was demonstrated by a sialogram. A diagnosis of Sjögren's syndrome was made and following treatment with potassium salt the patient recovered and was discharged. A 3 year follow-up revealed that the patient was well and living a normal life. Discussion was made regarding the etiological relationship between Sjögren's syndrome, MSK and RTA.
\end{abstract}

Key Words : Renal tubular acidosis (RTA), Sjügren's syndrome, Medullary sponge kidney (MSK), Sialectasis, Anti-DNA antibodies

Received for publication May 14, 1976

Reprint requests to: Tokugoro Tsunematsu, The

Second Department of Internal Medicine,

Faculty of Medicine, Kyoto University, 54, Shogoin Kawaramachi, Sakyo-ku,Kyoto, 606, Japan. 
In 1936, Butler et al reported a case of acidosis accompanied by nephrocalcinosis ${ }^{13}$ and since that time many cases of renal tubular acidosis (RTA) have reported in the literature. The fact that RTA is occasionally associated with hypergammaglobulinemia has been given increasing attention by clinicians. In $1962 \mathrm{Tsuda}$ et $\mathrm{al}^{2)}$ published the first case of RTA in Japan and some forty such cases can now be found in the Japanese literature. In 1963, Yawata and Kitamura ${ }^{32}$ reported a case of Sjögren's syndrome accompanied by RTA and hypergammaglobulinemia and the present authors recently encountered a 20 year old female with this syndrome plus RTA, medullary sponge kidney and multiple immunological abnormalities.

\section{CASE REPORT}

A 20-year-old woman was referred to Kyoto University Hospital because of quad. riplegia and arthralgia. Dental caries had increased during puberty and all teeth had decayed. Three years previous to admission she had a proteinuria and pain in the knee and ankle joints. The next year she entered Saiseikai Noe Hospital with complaints of fever, stomatitis, thirst, dry skin, vomiting and paralysis of the lower extremities, and laboratory examination revealed a hypopotassemia. The paralysis improved by oral administration of potassium salt. Subsequently, erythematous eruptions on both cheeks and arms developed. Recurrent attacks of painful swelling of both parotid glands appeared that year. One year before admission, myalgia of the lower extremities, alopecia and passage of urinary stones without pain or fever occurred. The same year, high fever and arthralgia developed and were followed by nodular erythema on the face, chest, back and extensor side of the extremities. A photosensitivity was noted but Raynaud's phenomenon was not present. Body temperature remained elevated despite antibiotic administration, however, antipyretica of the pyrazolon derivatives and steroid hormones were effective. Physical examination on admission revealed a female of average build who was fairly well nourished. General observations included: BP 116/70, pulse 100 per min., dry skin with small papules, erythema and nodules were noted but jaundice not present. Teeth of all her own had decayed, the thyroid gland was slightly enlarged, swelling of parotid glands not present, lymph nodes not palpable, chest and abdomen appeared normal, deformity and swelling of the joints was nil and in addition there was no evidence of muscular atrophy or neurological abnormalities.

Laboratory data are outlined in Table 1. The urine was positive for protein but repeated cultures all proved negative. Potassium clearance after loading 10\% sodium thiosulfate increased suggesting an increased urinary excretion of potassium. With ammonium chloride, 6.21 was the lowest $\mathrm{pH}$ in the urine samples despite a marked decrease in the plasma bicarbonate level. Such findings suggested marked impairment of renal acidification.

Abdominal X-rays revealed multiple, small calcifications which resembled bunches of grapes and such were evident in both kidneys. The IVP revealed these calcifications to be in the pyramid areas (Fig. 1) and such findings were characteristic of medullary sponge kidney (MSK).

Mild anemia and leukopenia were evident. Arterial blood gas analysis was $\mathrm{pH}$ 7.24, $\mathrm{P}_{\mathrm{CO}_{2}} 21 \mathrm{mmHg}$, bicarbonate $9.1 \mathrm{mEq} / \mathrm{L}$. There was a hypopotassemia and the sedimentation rate was $41 \mathrm{~mm} / \mathrm{hr}$. The gammaglobulin level was $3.2 \mathrm{~g} / \mathrm{dl}$ and rheumatoid, antinuclear factors and anti-thyroid and anti-DNA antibodies were positive. Thyroid function tests were normal. Although renal tubular reabsorption of phosphate, phosphate clearance and phosphate excretion index were all within normal limits, calcium loading tests revealed a slight hyperparathyroidism.

Salivary secretion was decreased and sialogram of the parotid gland showed a sialectasis (Fig. 2). The Schirmer's test was negative and keratoconjunctivitis sicca was not demonstrated. 
Table 1. Laboratory findings.

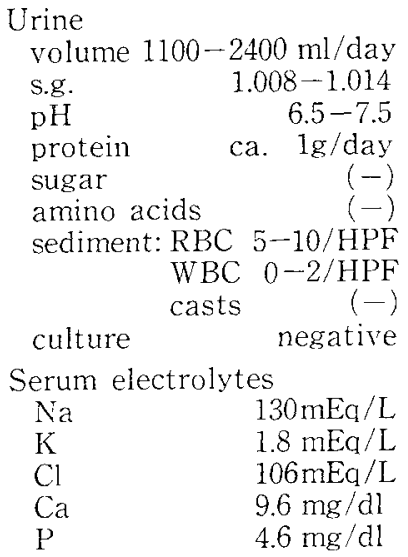

Immunological examinations Total serum proteins $9.5 \mathrm{~g} / \mathrm{dl}$

Albumin

$\alpha_{1}$-globulin

$\alpha_{2}$-globulin

$\beta$-globulin

$\gamma$-globulin

$\operatorname{IgG}$

$\operatorname{Ig} \mathrm{A}$

IgM

RA-factor

Coombs' test

Cold agglutinin

$51.6 \%$

$1.6 \%$

$5.2 \%$

$7.4 \%$

$34.2 \%$

$3160 \mathrm{mg} / \mathrm{dl}$

$296 \mathrm{mg} / \mathrm{dl}$

$324 \mathrm{mg} / \mathrm{dl}$

$(+)$

$(-)$

$(-)$

Blood

$\mathrm{Ht} \quad 11.8 \mathrm{~g} / \mathrm{dl}$

$\mathrm{RBC}$

WBC

$380 \times 10^{4} / \mathrm{mm}^{3}$

$3000 / \mathrm{mm}^{3}$

Platelets

$23.6 \times 10^{4} / \mathrm{mm}^{3}$

Arterial blood gas analysis

$\begin{array}{ll}\mathrm{pH} & 7.26 \\ \mathrm{PCO}_{2} & 21 \mathrm{mmHg} \\ \mathrm{PO}_{2} & 106.7 \mathrm{mmHg} \\ {\left[\mathrm{HCO}_{3}\right]} & 9.1 \mathrm{mEq} / \mathrm{L}\end{array}$

$\operatorname{ESR}\left(1^{\circ}\right)$

CRP

$41 \mathrm{~mm}$

$(-)$
Anti-microsomal antibody

Anti-thyroglobulin antibody

ANF

Anti-n DNA antibody

Wasserman's reaction

Mantoux reaction

LE cell phenomenon

Serum complement $\left(\mathrm{CH}_{50}\right)$

$10 \times 2^{9}$

$(-)$

$(+)$

$(+)$

$(-)$

$(+)$

$(-)$

42.1

Renal function

BUN $21 \mathrm{mg} / \mathrm{dl}$

Serum creatinine

Fishberg's concentrat ion test

and injection of Pitressin tannate

max. urine s.g.

PSP excretion rate

1.014

$15 \min 13 \%$

120 min $65 \%$

RPF

GFR

FF

$390 \mathrm{ml} / \mathrm{min}$

$50 \mathrm{ml} / \mathrm{min}$

0.128

$\mathrm{K}$ clearance $(10 \%$ sodium thiosulfate, $80 \mathrm{ml})$

before $\quad 10.0 \mathrm{ml} / \mathrm{min}$

after

$33.4 \mathrm{ml} / \mathrm{min}$

Ammonium chloride loading test min. plasma bicarbonate $10.3 \mathrm{mEq} / \mathrm{L}$ min. urinary $\mathrm{pH} \quad 6.21$

Thyroid function

BMR

$+9.5 \%$

Triosorb

$23.0 \%$

Tetrasorb

Parathyroid function

\% TRP

$8.5 \mu \mathrm{g} / \mathrm{dl}$

$P$ clearance

Phosphate excretion index

$89.9 \%$

$9.0 \mathrm{ml} / \mathrm{min}$

$-0.08$

$\mathrm{Ca}$ loading test

Parathyroid index

1.21

Urinary P fluctuation ratio $-11.4 \%$
Bony absorption of alveolar bone was advanced for her age, but other bones demonstrated no sign of osteoporosis.

A renal biopsy showed an infiltration of inflammatory cells, chiefly lymphocytes in the renal interstitial tissues. Thickening of the basement membranes of the glomeruli and Bowman's capsules and increased mesangial cells were demonstrated. A wireloop lesion-like change was noted (Fig. 3). Biopsy of the submandibular salivary gland revealed infiltration of the mononuclear cells of which some areas were dense and other scanty. Several ductules were atrophic and destruction of some of the acini was. evident. The thyroid gland showed a focal thyroiditis consisting of mild cellular infiltration and fibrosis.

With discontinuation of potassium salt and sodium bicarbonate on admission, a progression in metabolic acidosis occurred. and the serum potassium levels dropped to. 

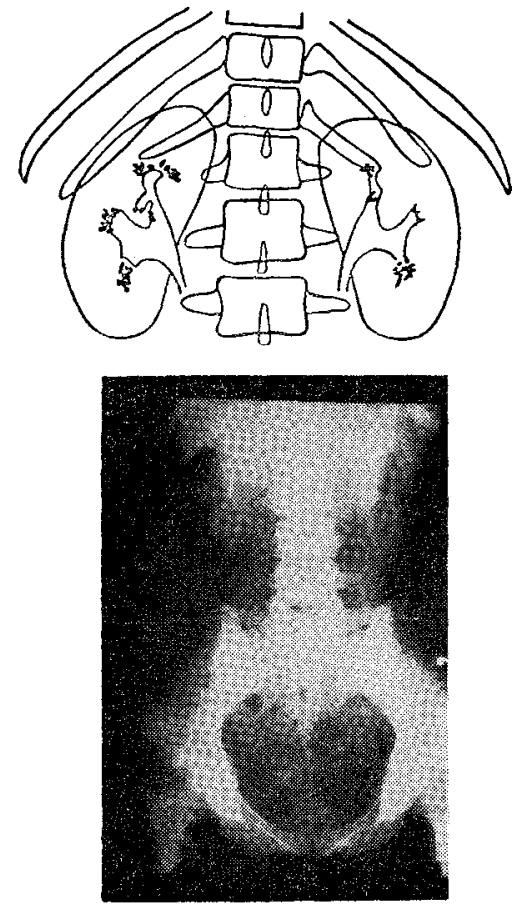

Fig. 1. Intravenous pyelogram. Note multiple calcifications in the renal pyramids appearing as bunches of grapes.

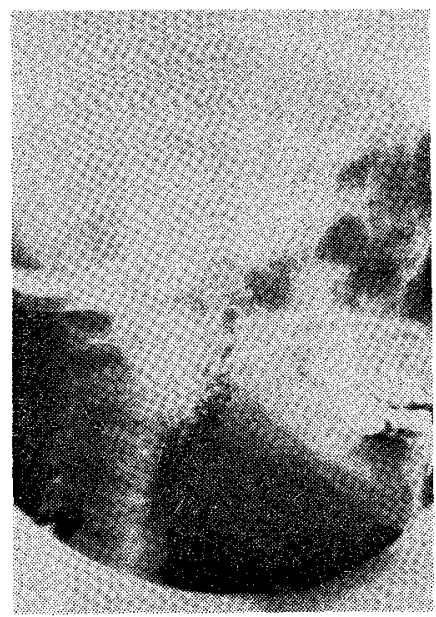

Fig. 2. Sialogram. Typical sialectasis is demonstrated.

$1.8 \mathrm{mEq} / \mathrm{L}$. Quadriplegia and myalgia soon followed. Treatment with potassium salt resulted in a rapid recovery.

\section{DISCUSSION}

There are two forms of RTA, the distal form (type 1) and a proximal form (type 2),

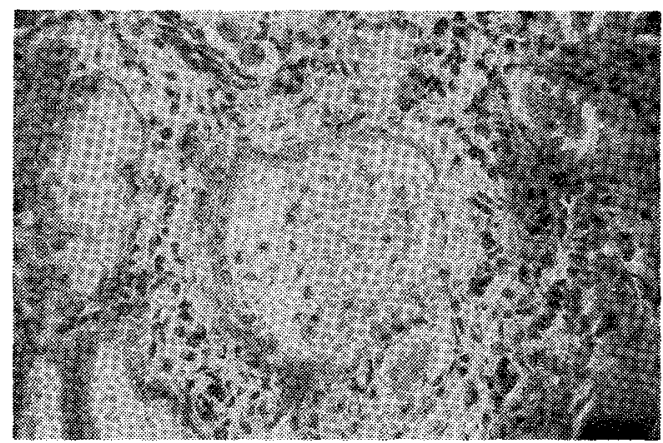

Fig. 3. Renal biopsy specimen. A glomerulus shows thickening of glemerular basement membrane and Bowman's capsule. Lymphocytic infiltration in the interstitial tissue is seen. (PAS stain)

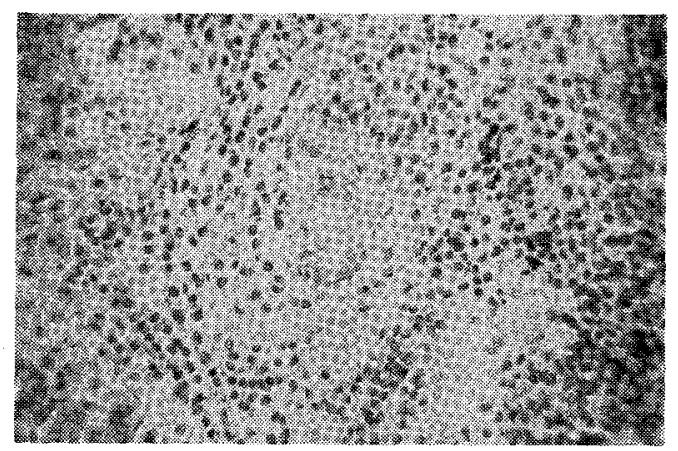

Fig. 4. Biopsy specimen of the submandibular gland. Considerable lymphocytic infiltration around a ductule is present. (Hematoxylin and eosin stain)

either of which may be primary or secondary manifestations ${ }^{4-6)}$. In distal $\mathrm{RTA}$, the $\mathrm{pH}$ gradient between blood and tubular fluid is inadequate. Proximal RTA is caused by a defect in the tubular reabsorption of bicarbonate and has a low renal threshold for bicarbonate excretion. The proximal form is characterized by the ability to adequately acidify urine when the plasma bicarbonate is below the renal threshold. The present case was considered to be a distal RTA as acidification of urine was markedly disturbed when plasma bicarbonate was lower than the renal threshold (Fig. 5).

RTA may be associated with a number of hypergammaglobulinemic syndromes, including $\mathrm{SLE}^{7)}$, Sjögren's syndrome ${ }^{8,9)}$, cryo- 


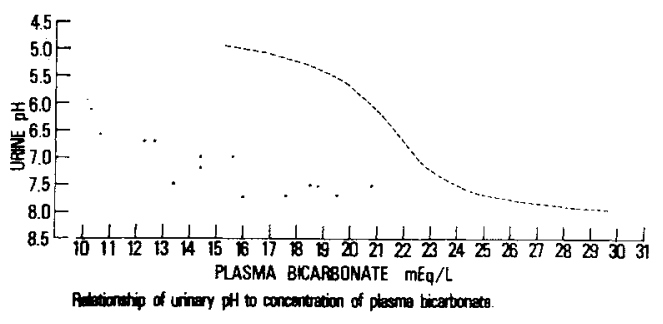

Fig. 5. Relationship of urinary $\mathrm{pH}$ to concentration of plasma bicarbonate. The broken curve represents the mean response in healthy adults.

globulinemia ${ }^{10)}$, multiple myeloma ${ }^{11}$, hypergammaglobulinemic purpura ${ }^{123}$, idiopathic hyperglobulinemia ${ }^{13)}$ and lupoid hepatitis ${ }^{14)}$.

In this case, multiple immunological ab. normalities such as hypergammaglobulinemia and positive tests for antinuclear, rheumatoid factors, anti-DNA and anti-thyroid antibodies were present. Wire-loop lesionlike change of the glomeruli was seen and leukopenia was present. In addition, facial erythema, polyarthritis, alopecia and photo. sensitivity were noted. These laboratory and clinical findings were met with diagnostic criteria for $\mathrm{SLE}^{15,16)}$. Although sicca syndrome was not prominent, recurrent swelling of the parotid glands, decreased salivary secretion, histological findings of the salivary gland and the picture of the sialogram suggested Sjögren's syndrome.

The association of SLE and malfunctioning exocrine glands is not frequently encountered while disturbances in salivary and lacrimal glands are principal features of Sjögren's syndrome. The underlying disroder in Sjögren's syndrome may be as in the case of SLE, a defect in the antibody producing system and clinical manifestations would include organic and functional abnormalities of the exocrine glands including the renal tubules. Should such a postulation be valid, then our patient demonstrated Sjögren's syndrome.

Antibodies to DNA are positive exclusively in SLE patients and such is also the case sometimes in Sjögren's syndrome, although the titer is rather low in the latter.

Another important feature of this case is association of $\mathrm{MSK}^{19}$. MSK is a congenital, non-hereditary anomaly of cystic dilatation of the collecting tubules frequently accompanied by mild renal function disturbances. Several cases of MSK associated with RTA have been reported. Deck ${ }^{18)}$ proposed three possible ways of explaining the combination of the two conditions. He thought it most probable that RTA is the result of pyelonephritis, a well known complication of MSK. Ekström et al ${ }^{19)}$ stated that all the kidneys they examined revealed inflammatory changes histologically. In our case, there was no increase of white blood cells in urinary sediment and repeated urine cultures were negative. Intravenous pyelography also showed no sign suggesting pyelonephritis.

It is difficult to explain the combination of MSK, RTA and Sjögren's syndrome. Popa ${ }^{20)}$ reported a child presenting RTA, hypergammaglobulinemic purpura and roentgenographic signs suggesting MSK. It appears unlikely that these combination is merely an accident. If examinations of the exocrine glands such as salivary and lacrimal glands are performed in addition to pyelography in patients with RTA and hypergammaglobulinemia, similar cases as described in this report might be increased in incidences.

It remains unknown that congenital anomalies of tissues or organs such as MSK play any role in the pathogenesis of auto. immune diseases. This case may offer a clue to the problem.

\section{REFERENCES}

1) Butler AM, et al: Dehydration and acidosis with calcification at renal tubules. J Pediat 8: 489, 1936.

2) Tsuda J, et al: A case of renal tubular acidosis. J Clin Pediat 15: 1256, 1962.

3) Yawata Y, Kitamura, S: Renal tubular acidosis. The Saishin-Igaku. 18: 1810, 1963. (in Japanese)

4) Soriano JR, et al: Bicarbonate reabsorption and hydrogen ion excretion in children with renal tubular acidosis. J Pediat $71: 802,1967$.

5) Shriano JR, Edelmann, CM: Renal tubular acidosis. Ann Rev Med 20; 363, 1969.

Jap J Med Vol 15, No 3 (July 1976) 
6) Morris RC Jr: Renal tubular acidosis. Mechanisms, classification and implications. New Eng J Med 281: 1405, 1969.

7) Tu WH, Shearn, MA: Systemic lupus erythematosus and Iatent renal tubular dysfunc. tion. Ann Int Med 67: 100, 1967.

8) Talal N, et al: Renal tubular acidosis, glomerulonephritis and immunologic factors in Sjogren's syndrome. Arthritis and Rheumatism 11: 774, 1968.

9) Shioji R, et al: Sjogren's syndrome and renal tubular acidosis. Amer J Med $48: 456,1970$.

10) LoSpalluto J, et al : Cryoglobulinemia based on interaction between a gamma macroglobulin and $7 \mathrm{~S}$ gamma globulin. Amer J Med 32: 142, 1962.

11) Sirota JH, Hamerman, D: Renal function studies in adult subject with the Fanconi syndrome. Amer J Med 16: 138, 1954.

12) Cohen A, Way BJ: The association of renal tubular acidosis with hyperglobulinemic purpura. Aust Ann Med 11: 189, 1962.

13) Morris RG Jr, Fudenberg, HH: Impaired renal acidification in patients with hypergammaglobulinemia. Medicine 46: 57, 1967.
14) Read AE, et al: Active "juvenile" cirrhosis considered as part of a systemic disease and the effect of corticosteroid therapy. Gut 4 : $378,1963$.

15) Stevens MS, et al: The clinical significance of extracellular material in LE cell preperation. New Eng J Med 268: 976, 1963.

16) Cohen AS, et al: Preliminary criteria for the classification of systemic lupus erythematosus. Bull Rheum Dis 21 : 643, 1971.

17) Spence HM, Singleton, $R$ : What is sponge kidney disease and where does it fit in the spectrum of cystic disorders? J Urol 107 : 176, 1972.

18) Deck MDF: Medullary sponge kidney with renal tubular acidosis, a report of 3 cases. J Urol 94: 330, 1965.

19) Ekstrüm $\mathrm{T}$, et al: Medullary sponge kidney. Stockholm: AImgvist and Wiskall. 1959.

20) Popa M, Stanescu V : Renal tubular acidosis and hypergammaglobulinaemic purpura in a 10 year old girl with roentgenographic signs suggesting medullary sponge kidney. Acta Pediat Scand 58 : 290, 1969. 